\title{
AVANÇOS, EQUíVOCOS E INSTABILIDADE DAS POLÍTICAS DE INOVAÇÃO NO BRASIL'
}

http://dx.doi.org/10.25091/

Solo1-3300201700030002

\author{
GLAUCO ARBiX* \\ MARIO SERGIO SALERNO** \\ GUILHERME AMARAL ${ }^{* * *}$ \\ LEONARDO MELO LINS****
}

\section{RESUMO}

O último ciclo de políticas industriais no Brasil, que se prolongou pelos dois mandatos do governo Lula até o impeachment de Dilma Rousseff, foi marcado por contradições que minaram sua eficácia. A retomada do ativismo de Estado combinou-se com a modernização do marco regulatório e com o reforço do apoio público inédito às atividades de P\&D empresarial. Porém, a perda de foco na inovação tecnológica realçou a necessidade de uma nova geração de políticas públicas voltadas para a elevação do patamar de competitividade da economia.

PALAVRAS-CHAVE: inovação; políticas públicas; tecnologia;

desenvolvimento econômico.

\section{Brazilian Innovation Policies: \\ Advances, Misconception, and Instability \\ ABSTRACT}

From 2004 to 2016 , under Lula da Silva and Dilma Rousseff's presidencies, a cycle of new industrial policies has been developed. State activism resulted in unprecedented support for R\&D and business innovation, even though marked by contradictions that undermined its effectiveness. The loss of focus on innovation has highlighted the need for a new generation of public policies to raise the standards of economic competitiveness.

KEYWORDS: innovation; public policies; technology; economic development.

[*] Universidade de São Paulo, São Paulo, SP, Brasil. E-mail: garbix@ usp.br.

[**] Universidade de São Paulo, São Paulo, SP, Brasil. E-mail: msalerno@ usp.br.

[***] Universidade de São Paulo, São Paulo, SP, Brasil. E-mail: guisgamaral @gmail.com.
A elaboração e execução de políticas públicas capazes de contribuir para mudanças estruturais de economias como a brasileira estão longe de serem consensuais. Tentações de curto prazo, de um lado, e protecionistas, de outro, pressionam em pinça um Estado despreparado ou que atua apenas lentamente para melhorar o ambiente de investimento, tornar o marco regulatório mais amigável à inovação ou implementar políticas de longo alcance, voltadas para melhorar a competitividade da economia. $O$ resultado desse despreparo 
é, quase sempre, o anúncio de políticas com foco difuso, sem prioridades claras, que se perdem muitas vezes no voluntarismo ou na rejeição, explícita ou não, de um conjunto de instrumentos que são utilizados intensamente por todos os países desenvolvidos e por emergentes, em especial os que competem com o Brasil. ${ }^{2}$

Críticos mais apressados, seja os que se arvoram modernos ou os que se apegam ao passado, esquecem muitas vezes que os bens científicos e tecnológicos, por sua natureza, são diferenciados.3 Exigem, por isso mesmo, respeito às suas dinâmicas próprias e à sua temporalidade distinta de outros bens físicos que compõem, por exemplo, a infraestrutura da economia - como estradas, portos, rodovias e outros. A incerteza e o risco que envolvem processos de geração do novo, aliados ao retorno social de que são portadores, exigem o envolvimento do setor público. 4 Para pesquisadores de perfil mais ortodoxo, o tom e o ruído da crítica diminuem, sem desaparecer, mesmo quando o debate se dá em torno de incentivos a pesquisa básica. ${ }^{5}$

Noentanto, ao se acompanhar a trajetória tecnológica de diferentes países, em que atuam governos com distintas colorações ideológicas, o fato é que praticamente todos serviram-se (ou ainda se servem) de um corpo de políticas, programas e instrumentos públicos de compartilhamento de riscos com o setor privado, com o objetivo de estimular o catching up e a dinamização de suas economias, para que não sejam ultrapassados tecnologicamente por países concorrentes. ${ }^{6}$

Essa proatividade do Estado ganhou peso especial após a crise financeira de 2007-2008, que empurrou vários governos a contrabalançar suas perdas com a regressão da atividade dos mercados e das empresas por meio de forte interferência na economia. Em busca da retomada do crescimento, um grande número de bancos centrais, de países avançados e emergentes -inclusive o Brasil, com o Programa de Sustentação do Investimento (PSI) — executaram políticas para ajudar a destravar suas economias, por meio da combinação de mecanismos macroeconômicos ${ }^{7}$ com investimentos em tecnologia e inovação.

Ainda que os avanços tecnológicos atuais tenham raízes na revolução do transistor, da microeletrônica e da computação, é difícil desvincular a intensidade da onda tecnológica atual, que sacode e questiona a indústria, serviços, agricultura e comércio em praticamente todos os níveis e países, do alto investimento público e privado, realizado para revitalizar empresas e as economias, em especial na Europa, Estados Unidos, Japão e China. ${ }^{8}$

Foram várias as trajetórias tecnológicas que foram beneficiadas pela concentração de investimentos durante a crise e que aceleraram o desenvolvimento de suas potencialidades. A longa maturação, iniciada em meados do século XX, com o estabelecimento dos principais pilares que viabilizaram a revolução da microeletrônica e das tecnologias
[****] Universidade de São Paulo, São Paulo, SP, Brasil. E-mail: leonardo melolins@gmail.com.

[1] Artigo baseado no estudo "Políticas de Inovação e Manufatura Avançada", financiado pela Agência Brasileira de Desenvolvimento Industrial (ABDI) e executado por pesquisadores do Cebrap, com supervisão técnica do Observatório da Inovação e Competitividade do Instituto de Estudos Avançados da USP (2016-2017).

[2] Block; Keller, 2011; Cimoli; Dosi; Stiglitz, 2009.

[3] Easterly, 2001; Flichy, 2003

[4] Jasanoff et al., 1995; Bijker, 1997; Nelson, 2006.

[5] Easterly, 2001.

[6] Cimoli; Dosi; Stiglitz, 2009; Stiglitz; Lin; Monga, 2013; Noman; Stiglitz, 2016.

[7] Uma das mais exuberantes políticas desenvolvidas com esse conteúdo foi executada nos Estados Unidos, entre 2007 e 2009. Nesse período o Federal Reserve System (FED, o banco central americano) aumentou drasticamente a oferta de dinheiro novo, por meio basicamente da negociação de government securities, para promover o crédito e aumentar a liquidez. O programa de quantitative easing (como é chamado) aumentou o volume dos assets do FED de menos de US \$ 1 trilhão em 2007 para mais de US\$ 4 trilhões em 2015 (EUA, 2017). De forma articulada, em 2009 , o Congresso aprovou o American Recovery Act (conhecido por Stimulus Bill), que sustentou a política do " $B u y$ American": por meio deste programa, toda e qualquer compra pública só poderia ser autorizada se os produtos fossem americanos. Essa injeção na economia foi acompanhada de uma série de iniciativas em outras áreas, em especial em CT\&I, que receberam recursos e incentivos inéditos. Com essa disposição, o governo Obama explicitava sua opção por políticas agressivas de interferência direta do Estado na atividade econômica e mesmo na vida de grandes empresas e bancos. Polêmicas por sua natureza, foram alvo de cerradas da ortodoxia neoclássica, mas também angariaram apoio de economistas como Larry 
Summers, Daron Acemoglu e Martin Feldstein (que não cabem no figurino da heterodoxia) e de expoentes como Paul Krugman e Joseph Stiglitz. Embora o debate não tenha se encerrado, prevalecem visões positivas sobre a efetividade dessas políticas para a recuperação da economia americana.

[8] Ver artigo nesta edição sobre as recentes políticas industriais dos EUA, Alemanha e China.

[9] Brynjolfsson; McAfee, 2014; OECD, 2015; 2017

[10] Rodrik, 2015.

[11] OECD, 2015, p.12.

[12] Rotolo etal., 2015, p. 215.

[13] Alexander et al., 2012. da informação e comunicação (TICs), produziu um corpo de tecnologias emergentes, que se articulam em torno de um tripé formado pela digitalização, integração e automação e que apontam para mudanças radicais nas economias e sociedades.

Em especial a partir do final do século passado, as economias mais avançadas passaram a se confrontar com uma miríade de novas possibilidades para seus sistemas produtivos e de serviços, que prenunciam mudanças de qualidade, para todos os países, decorrentes de inovações em materiais, imagem, robótica, impressão3 $\mathrm{D}$, internet das coisas (IоT) e, fundamentalmente, de sistemas digitais, integradores, de estocagem e analíticos que geram, reutilizam, processam e movimentam dados em escala, qualidade e velocidade inéditas. 9 Ou, como aponta Rodrik, ao discutir os avanços da biotecnologia, robótica e das tecnologias digitais, "a economia mundial está prestes a viver uma explosão de novas tecnologias". ${ }^{10}$

Na mesma chave, a OCDE destaca o potencial dos processos de inovação para o crescimento sustentável e o bem-estar das sociedades. Mas deixa seu alerta para a instabilidade que pode ser gerada por esse movimento disruptivo, que atinge a estrutura "das organizações e dos mercados, que fazem aflorar questões importantes relacionadas ao emprego, qualificação, privacidade e segurança, ou seja, ao modo como essas mudanças tecnológicas podem beneficiar as sociedades como um todo". ${ }^{11}$

Essas tecnologias emergentes caracterizam-se por serem radicalmente novas, se instalarem na intersecção entre a manufatura e os serviços, "[...] por crescerem aceleradamente e caracterizarem-se por um certo grau de coerência e pela capacidade de gerar impactos significativos na economia e sociedade". ${ }^{12} \mathrm{Na}$ realidade, alguns desses campos tecnológicos estão em formação, outros ainda em gestação, sem que a delimitação de seu alcance, de suas fronteiras e a determinação de seus relacionamentos sejam totalmente visíveis.

Masjáé possível visualizar a corrosão tendencial dos fundamentos atuais da competição, com o desenho de uma nova cartografia mundial da indústria; assim como os efeitos em cadeia das novas fontes de energia como substitutos do petróleo; e também o peso crescente dos novos materiais avançados-como a fibra de carbono, o grafeno e outros - que desafiam o mundo do alumínio e do aço; ou a diminuição das barreiras de entrada de negócios e empresas, suscitada pela computação e internet; ou ainda o avanço de algoritmos, sistemas computacionais e de análise, com base na coleta e armazenamento de enormes volumes de dados desestruturados. ${ }^{13}$

Por mais que esse panorama ainda seja restrito a alguns países (de modo especial, Alemanha, Estados Unidos, Japão e, entre os emergentes, a China) e a alguns segmentos da economia, é fundamental 
registrar que o mundo fabril, dos serviços e da agricultura já estão em plena mudança e, pelo ritmo, vão mudar ainda mais. E isso sem se aprofundar nas questões relacionadas ao mercado de trabalho, uma vez que a questão de fundo é que essas novas tecnologias são poupadoras de emprego e tendem a substituir trabalhadores com baixa ou média qualificação por um pequeno número de trabalhadores altamente qualificados. Ou, como afirma Rodrik, se é possível conceber um mundo em que as máquinas não geram necessariamente alto desemprego, "certamente será um mundo em que os maiores ganhos de produtividade serão abocanhados pelos donos das máquinas e das novas tecnologias. A maior parte da força de trabalho estará condenada aos baixos salários ou ao desemprego". ${ }^{14}$

Em outras palavras, a criação de emprego será mais difícil e, provavelmente, será concentrada em trabalhadores mais qualificadoscomo os engenheiros, cientistas da computação, designers, técnicos de TI, marketing e uma gama imensa de profissões híbridas, que mesclam competências para dar conta de seus objetivos. ${ }^{15}$ Exatamente por isso o perfil do emprego tende a ser muito distinto daquele que predominou no século XX, o que exigirá das empresas, universidades e dos planejadores públicos uma atenção redobrada sobre os mecanismos de cooperação que precisam ser instalados para a formulação adequada de políticas públicas.

Como enfatizaram Stiglitz, Lin e Monga, "[t] ransformações estruturais ocorrem sempre por conta de mudanças nas tecnologias, nas vantagens comparativas e na economia global". Ainda assim, para que esses processos tenham êxito, os países precisam aprender a migrar o capital humano e recursos financeiros escassos dos setores de baixo desempenho para as áreas de alta produtividade. Nesse sentido, somente serão eficazes as políticas públicas baseadas na articulação entre governo e a iniciativa privada, uma vez que "[...] esse processo, para ser eficiente, precisa dar conta das questões de externalidades e de coordenação. Os mercados por si mesmos não conseguem lidar muito bem com essas transformações estruturais". ${ }^{16}$

A retomada das políticas industriais no Brasil (em 2003-2004) incorporou, ainda que timidamente, a preocupação de se articular o setor público e o privado. De um lado, além da desconfiança que o setor empresarial nutria pelo governo no início do mandato do presidente Lula, as dificuldades de articulação remetiam ao longo período sem a utilização desse tipo de recurso público (mais de 25 anos desde a última tentativa, com os Planos Nacionais de Desenvolvimento); mas de outro, essa cooperação foi crescentemente assumida como essencial, uma vez que o corpo de planejadores do Estado, tendo em vista recorrentes insucessos, apresentava dificuldades para elaborar novas políticas para a elevação da produtividade da economia.
[14] Rodrik, 2015, p.2.

[15] Frey e Osborne (2017) estimam que $47 \%$ dos empregos nos EUA estão sob alto risco de serem extintos com o advento de inovações relacionadas à automação e digitalização da produção.

[16] Stiglitz; Lin; Monga, 2013, p. 10. 
[17] Edler; Fagerberg, 2017.

[18] Melo; Fucidji e Possas (2015) apresentam uma revisão desse debate na literatura.

[19] Mazzucato e Semieniuk (2017) apresentam um conjunto de inovações em políticas públicas que estimulam mudanças estruturais no sistema produtivo mundial.
Edler e Fagerberg, ${ }^{17}$ ao abordar os sistemas de inovação mais dinâmicos, enfatizaram que sua governança e a execução de políticas de tipo "mission-oriented", que se ordenam por prioridades e pela busca de resultados, caracterizam os sistemas mais eficientes da atualidade, como nos EUA, Alemanha, Inglaterra, Suécia, Coreia do Sul, Finlândia e Israel. No caso brasileiro, o desafio de cooperação público-privada, que já era grande, tornou-se maior com o advento das novas tecnologias. O risco de o país ficar ainda mais distante das práticas avançadas e de perder o atual ciclo de expansão tecnológica, como nos anos 1980 com a microeletrônica, será cada dia maior. Exatamente por isso, a nova geração de políticas industriais acompanhada de robustos sistemas de avaliação só fará sentido se tiver e mantiver a inovação como seu objeto central. ${ }^{18} \mathrm{U}$ ma diretriz simples e direta como essa permitirá ampliar e a profundar a necessária diversificação do sistema brasileiro de inovação, com novos programas, instrumentos e, principalmente, novas instituições mais adequadas para desenvolver iniciativas de encruzilhada, fruto de diferentes estratégias e cujo foco é a busca obstinada de resultados. ${ }^{19}$

\section{4-2014: AVANÇOS E OSCILAÇÕES NA CONDUÇÃO DAS POLÍTICAS dE INOVAÇÃO}

O Brasil possui uma longa história de políticas voltadas para incentivar a industrialização e a competitividade da economia nacional.

O longo ciclo marcado pela busca da substituição de importações era desafiado por uma sociedade agrária e por uma economia basicamente assentada em produtos intensivos em recursos naturais e insumos de baixo valor agregado. Com infraestrutura rudimentar e mão de obra sem escolaridade nem qualificação profissional, as várias versões de políticas industriais que frequentaram os anos 1950, 1960 e 1970 desenvolveram-se para estruturar prioritariamente a indústria pesada como instrumento para o crescimento econômico, em meio a uma sociedade não democrática, de competição controlada e forte presença do Estado, seu principal avalista, investidor e patrocinador.

Para os objetivos deste trabalho - e sem entrar na avaliação da qualidade do que foi alcançado-, é suficiente afirmar que o país conseguiu se industrializar, mas às custas de um enorme preço social, cuja parte mais visível foi a desigualdade social e regional, que se arrasta até os dias de hoje. No campo institucional, o nacional-desenvolvimentismo impregnou as engrenagens do Estado com múltiplas versões de protecionismo, sustentadas estruturalmente pelo insulamento da economia e tomadas como transitórias, ainda que permanentemente repostas pela via da política. O que era ino- 
vador no início - uma indústria, uma empresa - tem sua evolução relativizada e não raramente interrompida, para consolidar-se como estratégia de sobrevivência. Todo esse período, é certo, pede uma releitura para que se evitem erros semelhantes, mas também para que se alcancem as raízes que sustentam a baixa produtividade da economia, em especial da indústria brasileira.

Ao se iluminar as atividades de CT\&I no mesmo período, as diretrizes do Estado apontavam para o desempenho regular da economia como emulador natural da produção de conhecimento e novas técnicas. O crescimento traria naturalmente a necessidade de diversificação empresarial e, assim, de desenvolvimento de tecnologia e inovação. Mesmo com a criação do Conselho Nacional de Pesquisa (CNPq, atualmente Conselho Nacional de Desenvolvimento Científico e Tecnológico) e da Campanha Nacional de Aperfeiçoamento de Pessoal de Nível Superior (Capes, hoje Coordenação de Aperfeiçoamento de Pessoal de Nível Superior), em 1951, as atenções à produção endógena de tecnologia sempre foram residuais no corpo de preocupações dos governos desenvolvimentistas.

A estratégia adotada não previa tratamento especial para a CT\&I, nem mesmo um lugar entre os dispositivos de alavancagem do desenvolvimento econômico. Até o final do século passado, apesar das distintas estratégias que marcaram a condução da economia, tecnologia e inovação foram concebidas muito mais como subproduto do funcionamento regular dos mercados do que como instrumento voltado para impulsionar a atividade econômica.

O quadro a seguir apresenta um resumo das mudanças que envolveram as políticas industriais no país nos últimos sessenta anos.

Somente no início deste século, a inovação começa a ser colocada no centro das preocupações de governo, mais precisamente a partir da criação dos Fundos Setoriais, em 1999, e o início de seu funcionamento mais efetivo em 2001.

Esse reposicionamento não obedeceu a nenhuma lógica linear e tampouco ascendente, mesmo tendo em conta a extensão dos estudos que captaram o impacto da inovação e do desenvolvimento tecnológico na elevação do padrão dos sistemas produtivos. ${ }^{20}$

Assim como ocorreu com a ciência brasileira, a preocupação de se estruturar um sistema de inovação é recente. Foi somente nos últimos vinte anos que o Brasil passou a trabalhar com maior determinação a modelagem de uma arquitetura mais integrada e diversificada de inovação, com a articulação de programas, a edição de leis e regras e o surgimento de novas instituições.

Para isso, foram importantes as iniciativas para a formação de técnicos e engenheiros especializados e o reordenamento dos programas de pós-graduação efetivado pelo Ministério da Educação (MEC), a
[20] Acemoglu; Aghion; Zilibotti, 2006; Crowley; McCann, 2017; Mohnen; Hall, 2013; De Negri; Cavalcante, 2014; Pisano, 2010; Jorgenson; Ho; Samuels, 2012. 
QUADRO I

Contexto, vetores e visão das políticas industriais no Brasil

\begin{tabular}{|c|c|c|c|}
\hline Período & $1950-1980$ & $1990-1999$ & 200I-2010 \\
\hline Contexto & $\begin{array}{l}\text { - substituição de importações } \\
\text { - dirigismo estatal } \\
\text { - proteção comercial } \\
\text { - câmbio e preços administrados } \\
\text { - regime autoritário } \\
\text { - democracia restrita }\end{array}$ & $\begin{array}{l}\text { - elevação da qualidade via } \\
\text { gestão e TICs } \\
\text { - Estado regulador } \\
\text { - economia mais aberta } \\
\text { - controle da inflação e estabilidade } \\
\text { - econômica } \\
\text { - tripé macroeconômico } \\
\text { - regime democrático }\end{array}$ & $\begin{array}{l}\text { - estabilidade e diminuição } \\
\text { de pobreza e desigualdades } \\
\text { - Estado regulador e indutor } \\
\text { da transformação industrial } \\
\text { - ênfase na proatividade } \\
\text { do Estado }\end{array}$ \\
\hline Vetores & $\begin{array}{l}\text { - } \text { industrialização e } \\
\text { internalização de parte da } \\
\text { produção realizada no exterior }\end{array}$ & $\begin{array}{l}\text { - abertura e liberalização } \\
\text { - eficiência e qualidade } \\
\text { - políticas industriais fora } \\
\text { da estratégia ocorreram } \\
\text { pontualmente (autos) }\end{array}$ & $\begin{array}{l}\text { - } \text { inovação } \\
\text { - retorno de políticas industriais } \\
\text { e de grandes planos }\end{array}$ \\
\hline $\begin{array}{l}\text { Visão sobre } \\
\text { tecnologia e } \\
\text { inovação }\end{array}$ & $\begin{array}{l}\text { Industrialização e crescimento } \\
\text { econômico promoveriam } \\
\text { concorrência, geração de } \\
\text { tecnologia e elevação da } \\
\text { competitividade. }\end{array}$ & $\begin{array}{l}\text { Competição e abertura econômica } \\
\text { gerariam empresas mais } \\
\text { competitivas e inovadoras. }\end{array}$ & $\begin{array}{l}\text { Tecnologia e inovação nas } \\
\text { empresas dependem de } \\
\text { políticas públicas de incentivo. }\end{array}$ \\
\hline
\end{tabular}

Fonte: adaptado de Miranda e Mirra (2012).

[21] Os Fundos Setoriais são coordenados pelo Ministério de Ciência, Tecnologia e Inovação (MCTI) e executados legalmente pela Financiadora de Estudos e Projetos (Finep).
[22] Brasil, 2015 criação dos Fundos Setoriais ${ }^{21}$ e a criação do Fundo Nacional de Desenvolvimento Científico e Tecnológico (FNDCT).

A partir de 2003, o Brasil deu passos mais rápidos, com a aprovação da Lei da Inovação (Lei no 10.973/2004) e da Lei do Bem (Lei $\mathrm{n}^{\mathrm{O}}$ 11.196/2005), que viabilizaram incentivos à $\mathrm{P} \& \mathrm{D}$ semelhantes aos utilizados pelos países mais avançados. As mudanças no marco legal e regulatório abriram a possibilidade de se estruturar programas públicos de subvenção econômica (operada pela Finep), voltada para apoiar, via FNDCT, projetos de alto risco tecnológico. Essas medidas viabilizaram ainda uma rede de subsídios para a fixação de pesquisadores em empresas, a disseminação de programas de financiamento à inovação de capital empreendedor, assim como um arcabouço mais propício à interação universidade-empresa, com suporte da Finep, BNDES E CNPq.

Nesse período, as alterações do marco legal ocorreram em paralelo a um crescimento acentuado dos recursos e do investimento em inovação e tecnologia. Por exemplo, o dispêndio em P\&D no país apresentou crescimento de 1,01\% do PIB em 2003 para 1,24\% do PIB em $2013 .{ }^{22}$ 
O Quadro 2 apresenta as principais alterações no marco legal para a consolidação e expansão do Sistema Nacional de Inovação (SNI) no período iniciado em 2003.

Com a diversificação de dispositivos legais, o fomento à inovação tornou-se mais robusto. Com o Plano Nacional de CT\&I (PNCTI), de 2008 , a integração das ações relacionadas à inovação, coordenadas pelo então Ministério da Ciência e Tecnologia (MCT), tentaram se articular com as iniciativas de política industrial, coordenadas pelo Ministério do Desenvolvimento (MDIC), com resultados frágeis e apenas pontuais.

A criação da subvenção econômica pela Lei de Inovação, e a sua incorporação na Lei do FNDCT, assim como a equalização da taxa de juros e os incentivos fiscais passaram a constituir uma base de subsídios mais ampla para impulsionar a inovação. Apesar do avanço que significou a formatação legal da subvenção econômica, esse instrumento foi um dos mais atingidos pelos cortes e contingencia-

\section{QUADRO 2}

Alteração no marco legal de apoio à inovação

\begin{tabular}{|c|c|c|c|}
\hline Ano & Iniciativa & Dispositivo Legal & Planos e programas \\
\hline 1997 & $\begin{array}{c}\text { Marco regulatório do setor de petróleo } \\
\text { e gás e criação do primeiro Fundo Setorial } \\
\text { de CT\&I }\end{array}$ & Lei n ${ }^{\circ} 9.478 / 1997$ & $\begin{array}{c}\text { Programa de Apoio aos Núcleos de } \\
\text { Excelência (Pronex) }\end{array}$ \\
\hline $1999 / 2001$ & Criação dos Fundos Setoriais & $\begin{array}{c}\text { Leis n }{ }^{\circ} 9.991,9.992,9.993 \\
9.994 \text { e } 10.042 / 2000 \text { e } 10.146 \text { e } \\
10.332 / 2001\end{array}$ & $\begin{array}{l}\text { Política Nacional de Ciência, } \\
\text { Tecnologia e Inovação (PNCTI) }\end{array}$ \\
\hline \multirow[t]{2}{*}{$2003-2004$} & Lei de Inovação & Lei ${ }^{\circ} 10.493 / 2004$ & \multirow{2}{*}{$\begin{array}{l}\text { Política Industrial, Tecnolígica e de } \\
\text { Comércio Exterior (PITCE) }\end{array}$} \\
\hline & Nova Lei de Informática & Lei $n^{\circ} 11.077 / 2004$ & \\
\hline 2005 & Lei de Biossegurança & Lei $n^{\circ} 11.105 / 2005$ & \\
\hline \multirow[t]{2}{*}{2007} & Lei do Bem & Lei $n^{0} 11.196 / 2005$ & \\
\hline & Nova Lei do FNDCT & Lei n ${ }^{\circ} 11.540 / 2007$ & \\
\hline 2010 & $\begin{array}{c}\text { Fundo Social - Lei de Partilha, que tem } \\
\text { como receita os royalties do pré-sal }\end{array}$ & Lei ${ }^{\circ} 12.341 / 2010$ & $\begin{array}{c}\text { Plano de Ação em CT\&I (Pactii) } \\
\text { Estratégia Nacional de CT\&I (Encti) }\end{array}$ \\
\hline 2013 & Captação de recursos & Portaria MCT & Plano Inova Empresa \\
\hline 2014 & $\begin{array}{l}\text { Proposta de um novo padrão de organização } \\
\text { da produção de tecnologia e criação do Plano } \\
\text { Nacional de Plataformas do Conhecimento }\end{array}$ & Decreto $\mathrm{n}^{\circ} 8.269 / 2014$ & $\begin{array}{c}\text { Programa Nacional de Plataformas } \\
\text { do Conhecimento (PNPC) }\end{array}$ \\
\hline 2016 & $\begin{array}{l}\text { Novo Código de Ciência, } \\
\text { Tecnologia e Inovação }\end{array}$ & Lei ${ }^{\circ} 13.243 / 2016$ & \\
\hline
\end{tabular}


[23] Brasil, 2016.

[24] Maiores detalhes do código e do marco legal de inovação no Brasil ver "O Brasil e a nova onda de manufatura avançada: o que aprender com a Alemanha, China e Estados Unidos", publicado nesta edição de Novos Estudos. Também mais informações em Rauen (2016). mentos do Ministério da Fazenda. A subvenção é peça chave nos mecanismos de incentivo à inovação. Responde não pela diminuição do custo de capital, como no crédito, mas está diretamente ligada à redução do risco tecnológico. Exatamente as áreas de maior incerteza, ou seja, as que mais apresentam as maiores dificuldades para o desenvolvimento de P\&D empresarial. Mesmo em tempos de normalidade, esse risco comprime ou, pelo menos, tende a diminuir o volume de investimentos em projetos de maior ousadia. Nas crises, tradicionalmente, são os primeiros projetos a serem interrompidos ou postergados pelos empresários.

O Brasil não foge a essa prática, o que aumenta sua importância relativa quando se constata o ainda baixo nível do investimento em inovação apresentado pela iniciativa privada se comparado aos países avançados e mesmo aos emergentes. No caso brasileiro, é preciso, além da incerteza, incluir também no rol das dificuldades a historicamente baixa ambição tecnológica das empresas, que se expressa no reduzido número de inovações com alguma repercussão internacional.

A combinação da subvenção econômica com crédito, com transferências não reembolsáveis para programas de cooperação universidade-empresa, possível nesse período mais recente, começaram a consolidar uma gama de instrumentos de incentivo à inovação. Em todos os países avançados, esse é o lugar especial para a boa alocação de recursos públicos, pois permite compartilhar riscos e alavancar o investimento privado, ajudando, dessa forma, a elevar a ambição tecnológica das empresas.

Mais recentemente, o novo marco legal da inovação foi alterado, com a aprovação em 11 de janeiro de 2016, após sanção da presidente Dilma Rousseff da Lei no 13.243/2016.23 A nova lei é resultado de um processo de cerca de cinco anos de discussões entre instituições ligadas ao sistema de inovação que se dedicaram a aperfeiçoar a Lei de Inovação (e em outras nove leis relacionadas ao tema), de modo a reduzir obstáculos legais e burocráticos e conferir maior flexibilidade às instituições atuantes neste sistema. Mais ainda, o novo marco legal da inovação introduziu instrumentos novos, como o voucher, e tornou mais viáveis a utilização dos mecanismos das compras públicas e das encomendas tecnológicas. ${ }^{24}$

O reconhecimento desses avanços está no ponto de partida deste trabalho. Há, entretanto, um longo caminho pela frente que o país precisa percorrer para consolidar um sistema de inovação ágil, integrado, sem a tradicional trama burocrática e capaz de alocar recursos estáveis em áreas relevantes e prioritárias.

Na próxima seção serão abordados os três ciclos de políticas industriais desenvolvidos entre 2003 e 2016. 


\section{EM 2004, A ÊNFASE NA INOVAÇÃO}

A retomada das políticas industriais ativas deu-se com a Política Industrial, Tecnológica e de Comércio Exterior (PITCE), em março de 2004, que escolheu a inovação tecnológica como seu objetivo central. Suas diretrizes gerais buscavam dar suporte às estratégias de diferenciação de produtos e serviços nas empresas. Ainda que tardiamente em relação ao mundo,o Brasil ensaiava passos para sintonizar a indústria com as novas tendências tecnológicas mundiais. ${ }^{25}$

Nos anos 1990, a desconstrução do Estado desenvolvimentista não encontrou desenlace positivo na tradução de um novo modelo de desenvolvimento. Com exceção dos programas de qualidade dos anos $1990,{ }^{26}$ a abertura ainda que parcial da economia expôs a indústria à competição externa sem instrumentos de apoio, preparo e mão de obra qualificada. De fato, a surgiu como uma via de saída, ainda que pequena, para a crise da indústria, cujos sinais de atraso contrastavam com o avanço da computação e das TICs nos países avançados e mesmo em outros que, até a década de 1970, mostravam-se tão ou mais defasados quanto o Brasil, como a Coreia do Sul e Taiwan.

A PITCE descortinou novas modalidades de política industrial, rejeitou o protecionismo e diferenciou-se dos programas ocasionais e fragmentados da década de 1990 ao buscar a integração da tecnologia com a indústria e o comércio exterior. Ao integrar na estratégia industrial a perspectiva externa, a PITCE introduziu com peso o viés exportador, diferenciando-se de experiências passadas, historicamente voltadas para o mercado interno. $\mathrm{Na}$ base de seu diagnóstico estava a perda de competitividade da indústria e a necessidade de acelerar os processos de inovação, via a diferenciação de produtos e processos de maior valor agregado, de modo a capacitar a indústria para as exportações bem como para a internacionalização das empresas brasileiras. ${ }^{27}$

A PITCE abriu caminho para a aprovação da Lei da Inovação (Lei $\mathrm{n}^{\mathrm{O}}$ 10.973/2004) e da Lei do Bem (Lei no 11.196/2005), que definiram novos incentivos à $\mathrm{P} \& \mathrm{D}$, que guardavam semelhança com os sistemas mais avançados existentes fora do país. Após a Lei de Inovação, os primeiros editais públicos de subvenção econômica passaram a ser operados pela Finep com o objetivo de mitigar incertezas em projetos de alto risco tecnológico. Em 2005, com a Lei do Bem, mais um passo era dado para viabilizar uma rede de incentivos para programas de fixação de pesquisadores nas empresas, de isenções para a $P \& D$ industrial e um enquadramento mais favorável à interação universidade-empresa.

Juntamente com o avanço do marco regulatório-legal, seria criada a Agência Brasileira de Desenvolvimento Industrial (ABDI) com o objetivo expresso de coordenar as instâncias de governo, sendo
[25] Para análise da PITCE e os entraves e desafios ao desenvolvimento industrial, ver Salerno (2012).

[26] O Programa Brasileiro de Qualidade e Produtividade (PBQP) foi um esforço para a promoção da qualidade como elemento indutor da competitividade de indústria nacional. Para maiores detalhes dessa iniciativa e da política industrial no período, ver Guimarães (1996).

[27] Na sua exposição de motivos, pode-se ler que: "O desenvolvimento de novos produtos e usos possibilita a disputa e a conquista de novos mercados, acentuando o lugar cada vez mais importante que ocupa a capacitação para inovação industrial. É necessária uma alocação crescente de recursos públicos e privados para esse campo, para Pesquisa e Desenvolvimento (P\&D), para a alta qualificação do trabalho e do trabalhador e para a articulação de redes de conhecimento. Essa interação de diferentes áreas do saber, de métodos e alvos constitui uma das marcas fundamentais da Política Industrial, Tecnológica e de Comércio Exterior" (Brasil, 2003, p.4). 
que a presidência de seu conselho superior deveria ser ocupada, alternada e anualmente, pelo ministro do MDIC e do MCT. Na mesma direção, foi criado o Conselho Nacional de Desenvolvimento Industrial (CNDI), que contava com o comando direto do Presidente da República e com a participação de ministros (dentre eles, o da Fazenda, Planejamento e do Desenvolvimento), com representantes empresariais e da academia. Com o mesmo objetivo de fortalecer as instituições de articulação e fomento do sistema de inovação, seria criada a Empresa Brasileira de Pesquisa e Inovação Industrial (Embrapii), já no governo Dilma Rousseff, em 2013. Mais ágil, financiada basicamente pelo MCT e pelo MEC, a Embrapii nasceu inspirada pelos mecanismos de funcionamento dos institutos Fraunhofer, na Alemanha. Dotada de programas de médio prazo e com procedimentos operacionais mais simplificados e desburocratizados do que as agências tradicionais, a Embrapii caminha para consolidar seu espaço no sistema de inovação brasileiro.

Durante os dois mandatos do governo Lula, além da diversificação institucional, legal e das ferramentas de suporte à inovação, os recursos investidos em CT\&I aumentaram significativamentee só voltaram a decrescer no início do governo Dilma Rousseff, em 2011. É importante anotar que durante todo esse período novos personagens passaram a atuar com força no sistema de inovação, como o Ministério da Educação, da Defesa, da Agricultura e da Saúde; e também agências, como o BNDES, que em 2009, pela primeira vez, passou a contar com uma linha exclusiva para a inovação. Nessa trajetória, um dos toques negativos mais importantes ficou por conta do Instituto Nacional de Propriedade Industrial (Inpi), que, sem ter sido alvo de um programa robusto de recuperação, teve seus serviços debilitados e acabou por estampar a marca da precariedade no sistema patentário brasileiro.

A avaliação de longo prazo sugere que a postura mais proativa do Estado na sustentação das mudanças ajudou a multiplicar as articulações entre o setor público e o privado que, em contato com novos movimentos empresariais (como a Mobilização Empresarial pela Inovação, da Confederação Nacional da Indústria-CNI, e o Movimento Brasil Competitivo) e fóruns dedicados ao diálogo entre empresas, universidades e órgãos públicos, ajudaram a difundir a inovação e aceleraram o amadurecimento de todo o sistema nacional.

A PITCE teve como mérito maior a ousadia de colocar a inovação no centro dos desafios da indústria brasileira. No entanto, apesardo impulso que deu à modernização do aparato legal e institucional, a PITCE não alcançou efetividade. Carente de uma definição clara de instrumentos, recursos e de governança para sua implementação, a PITCE destacou-se por seus traços de experimentação, e suas fragilidades afloraram desdeo início de sua atuação, quando o grupo forte de ministros que fariam par- 
te do CNDI e do Conselho de Administração da ABDI, como o Ministro da Fazenda, da Casa Civil, do Planejamento e, da Secom, desfez-se logo após o lançamento da política. Com isso, as responsabilidades pela condução da PITCE recaíram sobre os ombros de um único ministério, o MDIC. Esseenfraquecimento político da ABDI exacerbou sua condição de agência de direito privado e parte do serviço social autônomo, o "sistema s". Como entidade paraestatal não integra, portanto, a administração direta nem a indireta do governo federal, o que dificulta em muito seu desempenho como articuladora de órgãos públicos (como ministérios e agências) para a execução da política industrial.

Mesmo com essas carências e desacertos, a PITCE ajudou a consolidar um diagnóstico sobre a indústria brasileira e a indicar os rumos da inovação para as empresas, propostas que seriam retomadas com maior intensidade dez anos depois, por iniciativas mais consistentes, em especial com o Plano Inova Empresa, conduzido pela Finep e pelo BNDES, com foco explícito na inovação.

\section{A PERDA DE FOCO DA PDP}

Em 2008 uma nova política industrial era anunciada, a Política de Desenvolvimento Produtivo (PDP), com foco principal no aumento do investimento agregado. Adequada para ajudar a economia, a PDP apresentou desequilíbrios como política industrial. A começar por descontinuar a centralidade na inovação enfatizada pela PITCE. Além da dispersão de seus objetivos, essa nova versão de política industrial fez uso intensivo de subsídios e de mecanismos de proteção contra a concorrência internacional. A PDP, executada basicamente pelo BNDES, não estava estruturada para diversificar o investimento nem para aumentar a P\&D nas empresas. Seu foco genérico levaria o BNDES a priorizar nada menos do que 24 setores da economia, sem conexão com as tendências tecnológicas que já despontavam e se consolidavam nas nações mais avançadas.

Acrise iniciada no sistema financeiro dos EUA em 2007 representava oportunidades e desafios para o Brasil, em especial no que se refere à absorção de tecnologia (via compra de ativos ou joint ventures com empresas dos países centrais) ou seu desenvolvimento doméstico (com recursos e instrumentos para P\&D empresarial). No entanto, a PDP pautou-se por passos menos ousados e deixou, de fato, de dar foco na inovação, ainda que tenha sido mantido em sua apresentação pública.

Lançada em maio de 2008 mais como uma medida do governo federal para minimizar os efeitos da crise econômica, a PDP seguiu apenas formalmente as trilhas abertas pela PITCE, em especial na definição de prioridades. A PITCE havia selecionado poucos segmentos prioritários (como a biotecnologia, a biomassa, a nanotecnologia), to- 
[28] Medidas que afetavam diretamente o desempenho da estrutura produtiva, priorizando ações nos planos fiscal e tributário.

[29] Fortalecimento das micro e pequenas empresas; expansão das exportações; integração produtiva com a América Latina e Caribe, com foco inicial no Mercosul; integração com a África; descentralização espacial da produção do país; e produção ambientalmente sustentável.

[30] APDP não definiu setores prioritários como na PITCE e anunciou três frentes de atuação: programas mobilizadores de áreas estratégicas, programas para consolidar e expandir a liderança e programas para fortalecer a competitividade (Brasil, 2008,pp.15-16).

[31] Apesar de o apoio à P\&D constar do PSI a partir de 2010, nenhuma contratação nessa linha foi feita até 2011, quando ocorreu a entrada da Finep também como operadora do PSI.

[32] Machado; Roitman, 2015. dos portadores de futuro, com grande potencial de retorno em termos de competitividade internacional e voltados para o desenvolvimento de uma indústria do futuro, e não para a revitalização da indústria do passado. Na PDP, foram muitos os setores escolhidos como prioridade, o que diluía ainda mais a atuação das agências públicas; além disso, a base de sustentação da PDP estava nas linhas de renúncia fiscal, que atendiam praticamente todo o conjunto da economia.

Para sua execução, o BNDES dividiu as ações da PDP em: Nível Sistêmico, ${ }^{28}$ Destaques Estratégicos ${ }^{29}$ e Programas Estruturantes. ${ }^{30} \mathrm{~A}$ característica marcante da PDP foi a multiplicidade de ações e objetivos, o que diminuiu sua identidade política e aumentou as dificuldades de governança, já presentes na PITCE.

Dos esforços da PDP nasceria o Programa de Sustentação do Investimento (PSI), estruturado diretamente pelo Tesouro Nacional, que foi importante para combater os efeitos da crise econômica originada nos Estados Unidos em 2007-2008, pelo menos até 2011. Contudo, do ponto de vista da estratégia de elevação da produtividade, o lançamento do PSI apenas reafirmaria a tendência de se colocar a inovação no mesmo nível de outros gargalos da economia. De fato, o PSI, construído como o maior programa de suporte ao investimento privado na história do Brasil, destinou apenas uma pequena parcela para a inovação e tecnologia, não mais do que $4 \%$ de sua dotação.

O documento oficial da PDP registrava que havia um ambiente econômico favorável, com altas reservas em dólar, redução da inflação e aumento do número de empregos gerados, mas que era preciso estimularo aumento da taxa de investimento privado, de modo a gerar um efeito em cascata por toda a estrutura produtiva. Por isso, cada um dos segmentos industriais contou com uma engenharia fiscal de modo a equacionar a redução de tributos e as desonerações daqueles que aumentassem o investimento. Com essas diretrizes, a PDP estabeleceu Quatro Metas-País, para 2010:

1. Aumentar a taxa de investimento da economia para $21 \%$ do PIB.

2. Ampliar os investimentos privados em P\&D para o,65\% do PIB. ${ }^{11}$

3. Ampliar para 1,25\% a participação brasileira nas exportações mundiais.

4.Aumentar em $10 \%$ o número de micro e pequenas empresas (MPE) exportadoras.

Infelizmente, nenhuma das quatro metas foi atingida.

\section{SUBSÍDIOS GENEROSOS E O DISTANCIAMENTO DA INOVACÃO}

O Plano Brasil Maior (PBM), de agosto de 2011 , deu continuidade à tendência de retomada de práticas já prenunciadas pela PDP. Mais do que isso, o PBM nasceu com o PSI já em seus limites de efetividade. ${ }^{22}$ 
Mesmo assim, o PSI foi o principal suporte para um programa de desonerações generalizadas para o setor produtivo, apresentado como a política industrial do primeiro governo Dilma.

Ainda que o PBM anunciasse a inovação e a elevação da competitividade como soluções para acelerar o crescimento da economia, as medidas definidas assemelharam-se mais às políticas anticíclicas do que a uma efetiva política industrial, como se pode ver em suas justificativas oficiais: "O Plano adotará medidas importantes de desoneração dos investimentos e das exportações para iniciar o enfrentamento da apreciação cambial, de avanço do crédito e aperfeiçoamento do marco regulatório da inovação, de fortalecimento da defesa comercial e ampliação de incentivos fiscais e facilitação de financiamentos para agregação de valor nacional e competitividade das cadeias produtivas". 33

Seu foco não era definitivamente a inovação nem a priorização de áreas de futuro ou mesmo de segmentos mais dinâmicos do ponto de vista tecnológico. Sua formulação, coordenada diretamente pelo Ministério da Fazenda, foi marcada por uma preocupação de horizontalidade em uma generosa política de subsídios que, além das questões fiscais que acarretou, pouco contribuiu para superar a ineficiente capacidade instalada. 34

O plano contemplou dezenove setores industriais e apresentou um conjunto de instrumentos diferenciados entre fiscais-tarifários (isenções tributárias e administração das tarifas de comércio exterior), financeiros (condições favoráveis de financiamento corporativo, via BNDES e Finep) e institucionais (definição de marco regulatório, constituição de carreiras públicas e criação de novas condições de ação para o Estado).

No que se refere às ações, o PBM definiu duas dimensões: uma setorial e outra sistêmica. Na primeira, o governo federal e o setor privado se encarregariam de desenvolver projetos chamados Diretrizes Estruturantes, ou seja: fortalecimento de cadeias produtivas; ampliação e criação de novas competências tecnológicas e de negócios; desenvolvimento das cadeias de suprimentos de energias; diversificação das exportações (mercados e produtos) e internacionalização corporativa; e consolidação de competências na economia do conhecimento natural.

A segunda dimensão do programa, a sistêmica, possuía dois objetivos: reduzir custos, acelerar o aumento da produtividade e promover bases mínimas de isonomia para as empresas brasileiras em relação a seus concorrentes internacionais e consolidar o SNI por meio da ampliação das competências científicas e tecnológicas e sua inserção nas empresas. Na prática, porém, o PBM também não priorizou a inovação tecnológica, apesar de ter estabelecido como mote a ideia de "inovar para competir, competir para crescer". $\mathrm{Na}$
[33] Brasil, 2011.

[34] A exceção seria o Inovar Auto, que, apesar dos problemas mais estratégicos e contestado na OMC, surpreendeu positivamente. 
contramão das políticas mais avançadas e sem os traços constitutivos de um corpo de política industrial, o PBM, ao tentar alavancar a economia, chegou a conceder maior incentivo às empresas menos inovadoras, em especial em sua lista de isenções da folha de pagamento, por apresentarem contingente maior de funcionários. Critério positivo quando a preocupação é o emprego, mas regressivo quando o tema é política de inovação.

\section{EM MEIO À CRISE, É CHAVE RETOMAR O INVESTIMENTO EM INOVAÇÃO E TECNOLOGIA}

O Brasil deu passos no rumo certo quando decidiu retomar as políticas industriais, mas escorregou ao perder o foco da inovação. E vai continuar marcando passo se não retomar o investimento em inovação e tecnologia em meio à crise atual.

O desenvolvimento tecnológico é processo de longa duração, que requer apoio, regras estáveis, previsibilidade institucional e condições diferenciais frente ao investimento tradicional.

Foi com esse entendimento que alguns programas e iniciativas foram concebidos e orientados para recuperar o foco em inovação diluído pela PDP e perdido no PBM.

Em março de 2013, o governo anunciou o Programa Inova Empresa (PIE), a ser executado pela Finep e pelo BNDES. Foi o primeiro na história do país inteiramente voltado para o apoio à inovação tecnológica. O programa representou um enorme avanço por conta: 1. do volume de investimento envolvido ( $R$ \$2,9 bilhões); 2 . da articulação interministerial (doze ministérios foram envolvidos, além da Finep, BNDES, Aneel, ANP e Sebrae); e 3. da qualidade dos instrumentos utilizados, com destaque para a inédita integração do crédito com a subvenção e recursos não reembolsáveis para universidades e centros de pesquisa.

Seu objetivo era ajudar a elevar o patamar do P\&D nas empresas e, assim, contribuir para o aumento da produtividade. Foram estruturados doze programas, em torno das áreas com maior possibilidade de desenvolvimento tecnológico, como saúde, energias renováveis, petróleo e gás, energia elétrica, defesa, aeroespacial, agricultura, sustentabilidade, tecnologias da informação e comunicação e tecnologias assistivas.

A demanda por recursos do plano foi surpreendente, o que demonstrou o apetite das empresas brasileiras por recursos para atividades de maior risco tecnológico: 2.715 empresas inscritas e 223 ICTs demandaram $\mathrm{R} \$ 98,7$ bilhões nos editais executados no âmbito do programa o volume efetivamente contratado ultrapassou a cifra de $\mathrm{R} \$ 30$ bilhões no final de 2014.35 
O êxito do Inova Empresa pavimentou o caminho para a elaboração do Programa Nacional de Plataformas do Conhecimento (PNPC), lançado por decreto pela Presidente da República em junho de 2014. Apesar ter sido criado nos moldes das melhores práticas internacionais ${ }^{6} 6$ e estruturado para viabilizar no Brasil o uso das encomendas tecnológicas, 37 o PN PC não deixou as gavetas do Planalto Central.

No entanto, sua elaboração e as discussões que suscitou, assim como sua aprovação pelo governo, sugere que é possível se pensar e se estruturar uma nova geração de políticas de inovação.

As características distintivas do PNPC remetem à reunião de diversos agentes e instituições, públicas e privadas, que se aglutinam em torno de projetos de P\&D que têm com objetivo o desenvolvimento tecnológico de ponta.

O programa diferenciou-se das atividades regulares de apoio à inovação, seja por conta:

1. Da sua lógica de resolução de problemas de interesse social e tecnológico, definidos diretamente pela Presidência da República; ou seja, o PNPC foi concebido como um processo top-down, em contraste diante da esmagadora maioria dos editais, chamadas e programas desenvolvidos no Brasil, caracterizados pela abordagem bottom-up, tanto nas universidades quanto nas empresas.

2. Da duração prevista para dez anos, para o desenvolvimento de projetos obrigatoriamente de cooperação entre empresa e universidade.

3. Da natureza de seu funding que, pela proposta, estaria marcado pela estabilidade dos repasses públicos.

4. Do volume de recursos públicos envolvidos, de até US \$500 milhões, que seriam somados ao investimento privado.

5. Dos seus objetivos orientados para a elevação do impacto tecnológico e social da inovação no Brasil.

A proposta do PNPC foi gestada prevendo-se uma forte articulação entre órgãos de governo, empresas e centros de pesquisa, cuja atividade de cooperação estaria voltada para a resolução de problemas sociais ou tecnológicos, como vacinas, medicamentos, novos materiais para aviões, drones para a agricultura e outros.

Por sua concepção, a definição e coordenação das plataformas seriam de competência do governo, mas a execução das ações de pesquisa seria compartilhada entre empresas, universidades e institutos de pesquisa.

O programa das plataformas persiste como símbolo do que pode ser feito para se estruturar uma nova geração de políticas de inovação, nas difíceis condições de um país que tem como cultura o curto prazo e definições estratégicas frágeis, quando não ausentes.
[36] Como exemplos internacionais de plataformas que inspiraram o modelo brasileiro, estão o Digital Manufacturing and Design Innovation Institute (Chicago, EUA), o Next Generation Power Electronics Manufacturing Innovation Institute (Carolina do Norte, EUA), o Institute of Science and Technology Austria (Áustria), o Advanced Manufacturing Research Centre (Boeing/University of Sheffield, na Inglaterra), o Graphene Research Centre (Basf/ National University of Singapore), o Cambridge Science Park (Reino Unido), o Clean Sky (União Europeia) e o MIT Energy Initiative.

[37] Nos Estados Unidos é marcante a presença da Defense Advanced Research Projects Agency (http://www.darpa.mil) como indutora e coordenadora da pesquisa de fronteira. A União Europeia conta com a iniciativa SmartGrids (http:// www.smartgrids.eu) que também trabalha para estabelecer a conexão entre atores capazes de gerar novas tecnologias, principalmente na área de energia, atuando na definição de estratégias, mobilização de competências e disseminação das capacidades para stakeholders. 
O sistema político brasileiro gerou partidos com enormes dificuldades para manter por um longo período programas e políticas públicas, mesmo quando estas exibem resultados positivos. Os ciclos eleitorais aliados à ação predatória que, lamentavelmente, marca boa parte das elites políticas do país, muitas vezes levam os governos a substituírem programas avançados por alternativas antigas ou apenas recicladas. $\mathrm{O}$ resultado desse comportamento, que expressa imaturidade institucional ou conservadorismo, são trajetórias erráticas, que frequentemente tiram o país da rota do desenvolvimento.

A inovação é apenas um capítulo a mais dessa trajetória de instabilidade e oscilação.

O governo Lula abriu uma fresta de esperança com a formulação de políticas com foco na inovação. No entanto, ainda em seu próprio mandato, esse foco se desfez e abriu caminho para a retomada de velhas políticas, mais íntimas do protecionismo e da tutela estatal.

É certo que a criação de uma verdadeira cultura da inovação no Brasil avançou, seja em termos institucionais, regulatórios, nas políticas, programas e instrumentos. Mas também é certo que há muito o que aperfeiçoar, consolidar e construir.

O Estado precisa se preparar para conta dos novos desafios colocados pelas mudanças tecnológicas que sacodem o mundo. As universidades precisam amadurecer e se internacionalizar aceleradamente, pois o fluxo de conhecimento é vital para o relançamento da economia brasileira. E as empresas, mais do que nunca, estão pressionadas a elevarem seu nível de P\&D e de inovação. Sem um árduo trabalho cooperativo entre o setor público, o privado e as universidades, o Brasil se distanciará ainda mais das práticas avançadas.

A agenda da inovação continua sendo chave para a recuperação do país. Essa é a síntese e o norte sugerido por este estudo. Que somente terá completado sua contribuição com as interações do debate público.

Recebido para publicação em 21 de agosto de 2017 . Aprovado para publicação em 18 de outubro de 2017

NOVOS ESTUDOS

109, novembro 2017

pp. 9-27

GLAUCO ARBIX é professor titular do Departamento de Sociologia da Universidade de São Paulo (USP), pesquisador do Observatório da Inovação e Competitividade do Instituto de Estudos Avançados (IEA-USP), ex-presidente da Finep (2011-2015) e do Ipea (2003-2006). Coordenador geral da pesquisa. Foi responsável pelas definições estratégicas da pesquisa, abordagem, consolidação de argumentos e redação final do artigo.

MARIO SERGio SALERNo é professor titular do Departamento de Engenharia de Produção da Escola Politécnica da USP, onde coordena o Laboratório de Gestão da Inovação. É cofundador do Observatório de Inovação e Competitividade do IEA-USP, ex-diretor do Ipea e da ABDI. Coordenador científico da pesquisa. Coordenou entrevistas com empresários e instituições e respondeu pela consolidação do balanço das várias versões da política industrial.

GUILHERME AMARAL é pesquisador do Observatório da Inovação e Competitividade e pós-doutorando no Departamento de Engenharia de Produção da Escola Politécnica da USP. Assistente de pesquisa. Ajudou a estruturar os argumentos analíticos e a preparar as várias versões do artigo.

LEONARDO MELO LINS é mestre e doutorando em sociologia pela USP. Foi pesquisador do Observatório de Inovação e Competitividade do IEA-USP e do Cebrap e atualmente é pesquisador do Cetic.br. Deu suporte para seleção, redação e levantamento de dados para a pesquisa. 


\section{REFERÊNCIAS}

Acemoglu, Daron; Aghion, Philippe; Zilibotti, Fabrizio. "Distance to Frontier, Selection, and Economic Growth". Journal of the European Economic Association, v. 4, n. 1, pp. 37-74, mar. 2006.

Alexander, Jeffrey et al. "Emergence as a Conceptual Framework for Understanding Scientific and Technological Progress".In:PICMET:Technology Management for Emerging Technologies, 2012,Vancouver.Proceedings... Vancouver: IEEE, 2012.pp. 1286-1292.

Bijker, Wiebe. Of Bicycles, Bakelites, and Bulbs: Toward a Theory of Sociotechnical Change. Cambridge: MIT Press, 1997. Block, Fred; Keller, Matthew R. State of Innovation: The U.S. Government's Role in Technology Development. Londres: Routledge, 2011.

Brasil. Diretrizes de política industrial, tecnológica e de comércio exterior. Brasília, 26 nov. 2003. Disponível em: http:// www.abdi.com.br/Estudo/Diretrizes_PITCE.pdf.Acesso em: 26 jul. 2017.

.Politica de desenvolvimento produtivo: inovare investir para sustentar o crescimento. Brasília: ABDI; BNDES, 2008. Disponível em: http://www.abdi.com.br/Estudo/Livreto\%2olancamento\%20PDP.pdf.Acesso em: 20 jun. 2017. . Ministério do Desenvolvimento, Indústria e Comércio Exterior. Agência Brasileira de Desenvolvimento Industrial. Plano Brasil Maior: inovar para competir, competir para crescer. Brasília: ABDI, 2011. Disponível em: http://www.abdi.com.br/Estudo/Relatorio\%20PBM\%202011-2014.pdf.Acesso em: 20 jun. 2017.

_. Ministério da Ciência, Tecnologia e Inovação. Financiadora de Estudos e Projetos (Finep). Relatório de gestão do exercício de 2014. Rio de Janeiro: Finep, 2015.

_. Lei n ${ }^{\circ}$ 13.243, de 11 de janeiro de 2016. Disponível em: http://www.planalto.gov.br/ccivil_o3/_Ato20152018/2016/Lei/L13243.htm. Acesso em: 18 jul. 2017.

Brynjolfsson, Erik; McAfee, Andrew. The Second Machine Age: Work, Progress, and Prosperity in a Time of Brilliant Technologies. Nova York: W. W. Norton, 2014.

Cimoli, Mario; Dosi, Giovanni; Stiglitz, Joseph E.(Orgs.).Industrial Policy and Development: The Political Economy of Capabilities Accumulation. Oxford: Oxford University Press, 2009.

Crowley, Frank; McCann, Philip. "Firm Innovation and Productivity in Europe:Evidence from Innovation-driven and Transition-driven Economies".Applied Economics, jul. 2017

De Negri, Fernanda; Cavalcante, Luiz Ricardo (Orgs.).Produtividade no Brasil:desempenho e determinantes, v. 1:Desempenho. Brasília:ABDI; Ipea, 2014.

Easterly, William. The Elusive Quest for Growth: Economists' Adventures and Misadventures in the Tropics. Cambridge: MIT Press, 2001.

Edler, Jakob; Fagerberg, Jan. "Innovation Policy: What, Why, and How". Oxford Review of Economic Policy, v. 33, n. 1, pp. 2-23, jan. 2017.

Estados Unidos da América (EUA). Federal Reserve System (FED). "Credit and Liquidity Programs and the Balance Sheet". Board of Governors of the Federal Reserve System, 24 maio 2017. Disponivel em: https://www. federalreserve.gov/monetarypolicy/bst.htm.Acesso em:31 out. 2017.

Flichy, Patrice. L'Innovation technique: récents développements en sciences socials vers une nouvelle théorie de l'innovation. Paris: La Découverte, 2003.

Frey, Carl Benedikt; Osborne, Michael. "The Future of Employment: How Susceptible Are Jobs to Computerization?”. Technological Forecasting \& Social Change, v. 114, pp. 254-280, jan. 2017.

Guimarães, Eduardo Augusto. “A experiência recente da política industrial no Brasil: uma avaliação". Texto para Discussão, Brasília, Ipea, n. 49, 1996.

Jasanoff, Sheila et al. (Orgs.). Handbook of Science and Technology Studies. Londres: Sage, 1995.

Jorgenson, DaleW.;Ho, Mun S.; Samuels, Jon D. “Information Technology and US Productivity Growth:Evidence from a Prototype Industry Production Account”. In: Mas, Matilde; Stehrer, Robert (Orgs.). Industrial Productivity in Europe: Growth and Crisis. Northampton: Edward Elgar, 2012.

Lester, Richard; Piore, Michael. Innovation: The Missing Dimension. Cambridge: Harvard University Press, 2004.

Machado, Luciano; Roitman, Fábio Brener. "Os efeitos do BNDES PSI sobre o investimento corrente e futuro das firmas industriais". Revista do BNDES, n. 44, pp. 89-122, dez. 2005.

Mazzucato, Mariana; Semieniuk, Gregor. "Public Financing of Innovation: New Questions". Oxford Review of Economic Policy, v.33, n. 1, pp. 24-48, 2017

Melo, Tatiana Massaroli; Fucidji, José Ricardo; Possas, Mario Luiz. "Política industrial como política de inovação: notas sobre o hiato tecnológico, políticas, recursos e atividades inovativas no Brasil”. Revista Brasileira de Inovação, v. 14,pp.11-36, jul.2015.

Miranda, Zil; Mirra, Evando. "Trajetórias do desenvolvimento do Brasil”. Revista USP. São Paulo, n. 93 , pp. 33-44, 2012.

Mohnen, Pierre; Hall, Bronwyn. "Innovation and Productivity: An Update". UNU-Merit Working Papers, n. $2013-021$, fev. 2013

Mokyr, Joel. The Gifts of Athena: Historical Origins of the Knowledge Economy. Princeton: Princeton University Press, 2002.

Nelson, Richard.Asfontes do crescimento econômico. Campinas: Ed. Unicamp, 2006.

Noman,Akbar; Stiglitz,Joseph E. Efficiency, Finance, and Varieties of Industrial Policy. Nova York: Columbia University Press, 2016.

Organisation for Economic Co-operation and Development (OECD). Digital Economy Outlook 2015. Paris: $\mathrm{OECD}, 2015$ 
The Next Production Revolution. Paris: OECD, 2017.

Pisano, Gary P. “The Evolution of Science-Based Business: Innovating How We Innovate”. Working Paper, Harvard Business School, n.10-062, 2010 .

Rauen, Cristiane Vianna. “O novo marco legal da inovação no Brasil:o que muda na relação ICT-Empresa?". Radar, Ipea, n. 43, pp. 21-35, fev. 2016.

Rodrik, Dani. "Rise of the Machines". World Finance, 9 mar. 2015.

Rotolo, Daniele et al. "Strategic Intelligence on Emerging Technologies: Scientometric Overlay Mapping”.Journal of the Association for Information Science and Technology, v. 68, n. 1, pp. 214-233, dez. 2015

Salerno, Mario Sergio. "Inovação tecnológica e trajetória recente da política industrial”. Revista USP, n. 93, pp. 45-59, 2012.

Stiglitz, Joseph; Lin, Justin Yifu; Monga, Célestin. "The Rejuvenation of Industrial Policy”. Policy Research Working Paper, The World Bank, n. 6.628, set. 2013. 